\title{
Transmission ratio distortion in the myotonic dystrophy locus in human preimplantation embryos
}

\author{
Nicola L Dean ${ }^{1,2,3}$, J Concepción Loredo-Osti ${ }^{3}$, T Mary Fujiwara ${ }^{3,4,5}$, Kenneth Morgan ${ }^{3,4,5}$, \\ Seang Lin Tan ${ }^{1,2,3}$, Anna K Naumova ${ }^{1,3,4}$ and Asangla Ao*,1,3,4 \\ ${ }^{1}$ Department of Obstetrics and Gynecology, McGill University, Montreal, Quebec, Canada; ${ }^{2}$ Department of \\ Experimental Medicine, McGill University, Montreal, Quebec, Canada; ${ }^{3}$ The Research Institute of the McGill University \\ Health Centre, Montreal, Quebec, Canada; ${ }^{4}$ Department of Human Genetics, McGill University, Montreal, Quebec, \\ Canada; ${ }^{5}$ Department of Medicine, McGill University, Montreal, Quebec, Canada
}

One form of myotonic dystrophy, dystrophia myotonica 1 (DM1), is caused by the expansion of a (CTG) repeat within the dystrophia myotonica-protein kinase (DMPK) gene located in chromosome region 19q13.3. Unaffected individuals carry alleles with repeat size (CTG) ${ }_{5-37}$, premutation carriers $(C T G)_{38-49}$ and DM1 affected individuals (CTG) $50-6000$. Preferential transmission both of expanded repeats from DM1-affected parents and larger DMPK alleles in the normal-size range have been reported in live-born offspring. To determine the moment in development when transmission ratio distortion (TRD) for larger normal-size $D M P K$ alleles is generated, the transmission from heterozygous parents with one repeat within

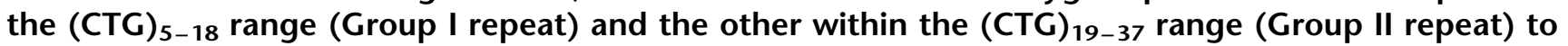
human preimplantation embryos was analysed. A statistically significant TRD of 59\% (95\% confidence interval of 54-64) in favour of Group II repeats from both mothers and fathers was observed in preimplantation embryos, which remained significant when female embryos were considered separately. In contrast, no significant TRD was detected for repeats from informative Group I/Group I parents. Our analysis showed that Group II repeats specifically were preferentially transmitted in human preimplantation embryos. We suggest that TRD, in Group II repeats at the DMPK locus, is likely to result from events occurring at or around the time of fertilisation.

European Journal of Human Genetics (2006) 14, 299-306. doi:10.1038/sj.ejhg.5201559; published online 4 January 2006

Keywords: human preimplantation embryos; myotonic dystrophy; normal-size DM repeats; transmission ratio distortion

\section{Introduction}

A fundamental principle of Mendelian genetics is the probability of equal transmission, from parent to offspring, of the two alleles at any given diploid locus. However,

${ }^{*}$ Correspondence: Dr. A Ao, Department of Obstetrics and Gynecology Research Division, Royal Victoria Hospital F3.16, 687 Pine Avenue West, Montreal, Quebec, Canada H3A 1A1. Tel: + 15148421231 ext 34741; Fax: + 1514843 1662; E-mail: asangla.ao@muhc.mcgill.ca

Received 15 September 2005; revised 31 October 2005; accepted 18 November 2005; published online 4 January 2006 deviation from Mendelian 1:1 segregation ratios, also termed transmission ratio distortion (TRD), has been documented for different species and different genetic loci (reviewed by Lyttle). ${ }^{1}$ In humans, allele-specific TRD, which refers to preferential transmission of a particular allele(s) has been reported for the repeat region near the insulin gene (INS-IGF2 VNTR), ${ }^{2}$ and for larger trinucleotide repeats in the genes responsible for myotonic dystrophy $(D M P K),{ }^{3-7}$ Machado-Joseph disease (ATXN3), ${ }^{8-10}$ fragile $\mathrm{X}$ syndrome $(F M R 1),{ }^{11}$ spino-cerebellar ataxia type 1 (ATXN1), ${ }^{9}$ spino-cerebellar ataxia type 7 (ATXN7), ${ }^{12}$ and 
dentatorubral-pallidoluysian atrophy $(A T N 1) .{ }^{8}$ The common feature of these trinucleotide repeats is that they cause a progressive pathological phenotype when there is an expansion of the repeat and, in general, genetic anticipation is seen, with a progressively earlier onset and increased severity of disease, as the condition is transmitted to successive generations of a family. ${ }^{13}$

The human dystrophia myotonica-protein kinase $(D M P K)$ gene is located in chromosome region $19 \mathrm{q} 13.3$ and contains a $(\mathrm{CTG})_{n}$ repeat in its $3^{\prime}$ untranslated region. ${ }^{14,15}$ Expansion of this repeat causes dystrophia myotonica 1 (DM1 [MIM 160900] Online Mendelian Inheritance in Man http://www.ncbi.nlm.nih.gov/Omim), an autosomal dominant disorder, which is the most common form of adult muscular dystrophy. DM1 has variable phenotypic expression ranging from presenile cataracts in some mildly affected individuals to the severe congenital form with general muscular hypotonia, respiratory distress, increased neonatal mortality rate, delayed motor development, and mental retardation. ${ }^{16}$ The phenotypic expression and age of onset are correlated with the length of the repeat expansion. ${ }^{17,18}$ Individuals with $(\mathrm{CTG})_{>1000-6000}$ repeats develop the congenital disease. ${ }^{14}$ Adult-onset patients carry DMPK alleles with (CTG) $100-1000$ repeats, mildly affected or very late onset patients carry alleles with $(\mathrm{CTG})_{50-150}$ repeats, whereas premutation carriers have (CTG) $38-49$ repeats, and unaffected individuals carry alleles with $(\mathrm{CTG})_{5-37}$ repeats. ${ }^{14}$

Preferential transmission of expanded (CTG) $n$ repeats from DM1-affected parents to live-born offspring has been reported in DM1 families. ${ }^{4,6,7}$ Moreover, preferential transmission of the larger of the two $(\mathrm{CTG})_{n}$ repeats in the normal-size range from parents to live-born offspring has been found in families with no DM1. ${ }^{3,5,19}$

The mechanism of such preferential transmission of larger DMPK alleles remains unclear. In principle, TRD may result from events that occur before (meiotic drive or preferential survival of gametes), at the time of, or after fertilisation (embryonic death). To determine the timing of TRD and thereby clarify its mechanism, transmission of $D M P K$ alleles was studied in individual spermatozoa of three heterozygous males each with a (CTG) $)_{5}$ and a $(\mathrm{CTG})_{20-37}$ repeat. $^{20}$ No segregation distortion was observed, leading to the conclusion that TRD resulted from events following sperm ejaculation. Thus, TRD is present among live-born offspring and apparently, at least in the male germline, results from events at the time or after fertilisation.

It has been suggested that larger normal-size (CTG) $)_{19-37}$ repeats, unlike $(\mathrm{CTG})_{5-18}$ repeats, may be susceptible to intergenerational instability and, therefore, preferential transmission of the (CTG) ${ }_{19-37}$ repeats provides a reservoir for future expanded alleles in the population. ${ }^{21}$ Carey et $a l^{3}$ selected a cutoff point of $(\mathrm{CTG})_{19}$ repeats for their study of transmission of DMPK alleles in the normal-size range.
Based on the functional importance of the (CTG) 19-37 repeats for the aetiology of DM1 and the evidence for their preferential transmission, ${ }^{3}$ we have selected the same cutoff point. To simplify our terminology, we will refer to smaller normal-size DMPK alleles with (CTG) $5-18$ as Group I repeats, and to larger normal-size alleles with $(\mathrm{CTG})_{19-37}$ as Group II repeats. To further investigate the timing of the occurrence of TRD of normal-size range repeats in the human DMPK locus and as a next step in the elucidation of its mechanism, we conducted an analysis of transmission of larger normal-size DMPK alleles, from parents to human preimplantation embryos. Parent-of-origin and gender-ofembryo effects have been previously described in TRD studies both on larger normal-size and expanded DMPK alleles to live-born offspring. ${ }^{3-7,19}$ Therefore, we also analysed our results according to the sex of the transmitting parent and sex of the embryo.

\section{Materials and methods Subjects}

The length of DMPK alleles was determined from consenting patients that underwent in vitro fertilisation (IVF) at the McGill Reproductive Centre from September 2001 to October 2003 (McGill University, Montreal, Quebec, Canada). No exclusion was made based on age of patients, cause of infertility, or ethnicity of couples. The research ethics review board of the Royal Victoria Hospital, McGill University Health Centre approved this study. Couples where at least one of the partners was heterozygous for one Group I and one Group II repeat were approached, after their embryos had been selected for transfer to the female and for embryo freezing, for permission to test the remaining embryos. If agreeable, each couple signed consent to permit the use of their embryos in this study.

\section{Determination of the length of maternal and paternal DMPK $(\mathrm{CTG})_{n}$ repeats}

The length of the DMPK alleles of the mother was determined by polymerase chain reaction (PCR) on the collected cumulus cells surrounding the oocyte. Shortly after the oocyte retrieval, cumulus cells (approximating $20 \%$ of the total cumulus mass) were removed from two oocytes using a sterile technique. These cumulus cells were disaggregated in 80 IU hyaluronidase (Vitrolife, Goteburg, Sweden) and washed in sterile phosphate-buffered saline (PBS) (Sigma, Oakville, ON, Canada). A $1.5 \mu \mathrm{l}$ aliquot of cumulus cells was added to each of two labelled, sterile, $0.2 \mathrm{ml}$ tubes containing $5 \mu \mathrm{l}$ of alkaline lysis buffer (LB), ${ }^{22}$ and overlaid with sterile oil. The allele size of the father was determined by PCR on spermatozoa from two $3 \mu \mathrm{l}$ aliquots of the sperm preparation used for IVF, using LB and oil as above. Each aliquot of cumulus cells (from mother) and sperm (from father) was lysed by heating to $65^{\circ} \mathrm{C}$ for $15 \mathrm{~min}$. 
A fluorescent, hemi-nested, PCR was carried out to amplify the $(\mathrm{CTG})_{n}$ repeat region of the DMPK gene. ${ }^{22}$ Reactions for the first round of PCR were carried out in a total volume of $50 \mu \mathrm{l}$ and included 5\% dimethylsulphoxide (DMSO), neutralisation buffer (900 mM Tris- $\mathrm{HCl}(\mathrm{pH} \mathrm{8.3),}$ $300 \mathrm{mM} \mathrm{KCl}, 200 \mathrm{mM} \mathrm{HCl}$ ), potassium-free PCR buffer (25 mM $\mathrm{MgCl}_{2}, 100 \mathrm{~mm}$ Tris-HCl (pH 8.3)), $100 \mu \mathrm{M}$ of each dNTP, $1 \mathrm{U}$ of Taq polymerase (Qiagen, Mississauga, ON, Canada), and $0.4 \mu \mathrm{M}$ of DMPK primers, forward (DMF) and outer reverse (DMOR) (Intergrated DNA Technology, IA, USA). The DMF primer was labelled with CY5 fluorescent dye. The PCR was carried out on a PTC-200 thermocycler (MJ Research, Watertown, MA, USA) using in the first round the following program: $5 \mathrm{~min}$ denaturation at $96^{\circ} \mathrm{C}$, followed by 15 cycles of $1 \mathrm{~min}$ at $96^{\circ} \mathrm{C}, 45 \mathrm{~s}$ at $60^{\circ} \mathrm{C}$ and $1 \mathrm{~min}$ at $72^{\circ} \mathrm{C}$, followed by $5 \mathrm{~min}$ at $72^{\circ} \mathrm{C}$.

For the second round of DNA amplification, $2 \mu$ l of the first-round products were added to reaction mixes in a total volume of $30 \mu \mathrm{l}$ with PCR buffer (200 mM Tris- $\mathrm{HCl}$ (pH 8.4), $500 \mathrm{~mm} \mathrm{KCl}, 15 \mathrm{~mm} \mathrm{MgCl}_{2}$ ), $100 \mu \mathrm{M}$ dNTPs, $1 \mathrm{U}$ of Taq polymerase (Qiagen, Mississauga, ON, Canada), and $0.4 \mu \mathrm{M}$ of DMF and DMPK reverse (DMR) primers (Intergrated DNA Technology, IA, USA). The cycling conditions were $5 \mathrm{~min}$ denaturation at $96^{\circ} \mathrm{C}$, followed by 10 cycles of $30 \mathrm{~s}$ at $96^{\circ} \mathrm{C}$, $45 \mathrm{~s}$ at $62^{\circ} \mathrm{C}$ and $1 \mathrm{~min}$ at $70^{\circ} \mathrm{C}$, then 15 cycles of $1 \mathrm{~min}$ at $94^{\circ} \mathrm{C}, 45 \mathrm{~s}$ at $62^{\circ} \mathrm{C}$ and $1 \mathrm{~min}$ at $70^{\circ} \mathrm{C}$, and finally $5 \mathrm{~min}$ at $72^{\circ} \mathrm{C}$.

Fluorescently labelled amplified DNA ( $3 \mu \mathrm{l})$ were mixed with $5 \mu \mathrm{l}$ of loading dye and denatured for $3 \mathrm{~min}$ at $90^{\circ} \mathrm{C}$ prior to the samples being loaded onto a $9 \%$ polyacrylamide denaturing gel and run on an ALF Automated DNA Sequencer (Amersham Pharmacia Biotech, Montreal, QC, Canada). DNA was visualised as fluorescent peaks using the instrument's packaged computer software. A fluorescently labelled 50-500 bp marker (Amersham Pharmacia Biotech, Montreal, QC, Canada) was loaded onto each gel and used to size peak fragments.

\section{Collection of embryos}

Every donated embryo was tested with no selection being made on the basis of developmental stage. The inclusion criteria for the study were that the fertilised embryo was not selected to be transferred to the female or to be frozen. Hence, preimplantation embryos from the two-cell stage to blastocyst were included. Each donated embryo was incubated for $5 \mathrm{~min}$ in $\mathrm{Ca}^{2+}$ and $\mathrm{Mg}^{2+}$ free media (Cook Canada Inc., Stouffille, ON, Canada) to allow the decompaction of blastomeres. The zona pellucida was removed using acid Tyrode's solution ( $\mathrm{pH} 2.5$ ) (Sigma, Oakville, ON, Canada) and the cells washed through three drops of PBS containing $4 \mathrm{mg} / \mathrm{ml}$ bovine serum albumin (Sigma, Oakville, ON, Canada). The blastomeres were then disaggregated using a sterile pulled-glass pipette and pipetted into one to three tubes, depending on the number of cells present, which contained LB and were overlaid with sterile oil. Grouping of cells for the PCR assay ensured that results were obtained from the maximum number of embryos. After collection, all samples were centrifuged and kept at $-80^{\circ} \mathrm{C}$ for at least $20 \mathrm{~min}$ before being incubated at $65^{\circ} \mathrm{C}$ for $15 \mathrm{~min}$ to lyse the cells. For each embryo, a sample of media from the last drop in which the blastomeres had been washed was placed in a PCR tube with $5 \mu \mathrm{l} \mathrm{LB}$ to act as a negative control for that embryo.

\section{Genotyping of donated embryos}

A multiplex, hemi-nested, fluorescent PCR was carried out to amplify the DMPK $(\mathrm{CTG})_{n}$ repeat region along with a sequence of the amelogenin gene $(A M E)$ to determine gender. The primer sequences to amplify the $A M E$ region were taken from Ray et al. ${ }^{23}$ The $A M E$ primers allowed the detection of two sequences, one on the $\mathrm{X}$ and one on the $\mathrm{Y}$ chromosome that were different in size to distinguish the gender of each embryo by fragment length analysis. Females have one $115 \mathrm{bp}$ amplified fragment, whereas males have two fragments of 115 and $121 \mathrm{bp}$. The PCR conditions in the first round were similar to those employed for the determination of the DMPK parental allele sizes except that $0.05 \mu \mathrm{M}$ of $A M E$ primers, outer forward (AME-OF) and outer reverse (AME-OR) (Intergrated DNA Technology, IA, USA), were added. For the second round $D M P K$ and $A M E$ were amplified separately. For $D M P K$, the reaction mixes were the same as above. For $A M E, 3 \mu \mathrm{l}$ of the first-round products were added to reaction mixes in a total volume of $30 \mu \mathrm{l}$ with PCR buffer, $50 \mu \mathrm{M}$ dNTPs, $1 \mathrm{U}$ of Taq polymerase (Qiagen, Mississauga, $\mathrm{ON}$, Canada), and $0.25 \mu \mathrm{M}$ of $A M E$ primers, inner forward (AME-IF) and AME-OR (Intergrated DNA Technology, IA, USA). The AME-IF primer was labelled with CY5 fluorescent dye. The PCR conditions for both reactions were similar to those used in the second round for the parental alleles except that 28 cycles were used in total, 10 cycles followed by 18 cycles. The samples were run on an ALF Automated DNA Sequencer as above using 3 and $5 \mu$ l of amplified $D M P K$ and $A M E$ products, respectively.

The printouts from all aliquots amplified from each embryo were compared to ensure they gave the same result and each negative control was checked to ensure there was no amplification. For each embryo, the DMPK genotype and embryo gender were recorded.

\section{Reliability of genotyping}

Amplification rates for DMPK and AME were 95 and $94 \%$ and rates of allele dropout were 12 and $6 \%$, respectively. Allele dropout is the failure of amplification of one allele in a heterozygous sample and is observed when single cells or very small quantities of DNA are amplified. ${ }^{24}$ To confirm the genotypes, duplicate or triplicate samples were run for $86 \%(293 / 341)$ of the embryos, and complete results for the size of the inherited DMPK alleles and the gender were obtained for all but six of the embryos tested. 


\section{Statistical analysis}

Deviation from 1:1 segregation was tested using the exact binomial test in $\mathrm{R}$ for Windows, version 1.8.0. (The $\mathrm{R}$ Project for Statistical Computing, http://www.r-project. org). Reported $P$-values were not corrected for multiple testing. Taking into account for at most nine comparisons, we considered a $P$-value of $<0.0056$ to be statistically significant. All other variables were analysed using a twotailed $t$-test or a two-sided $\chi^{2}$ test for independent variables. The exact test in GENEPOP, version 3.4 was used to test for Hardy-Weinberg equilibrium (GENEPOP, http://wbiomed. curtin.edu.au/genepop). ${ }^{25}$

\section{Results}

Inclusion criteria and characteristics of participating couples

In total, 234 couples (468 individuals) undergoing IVF consented to enter the study and will be further referred to

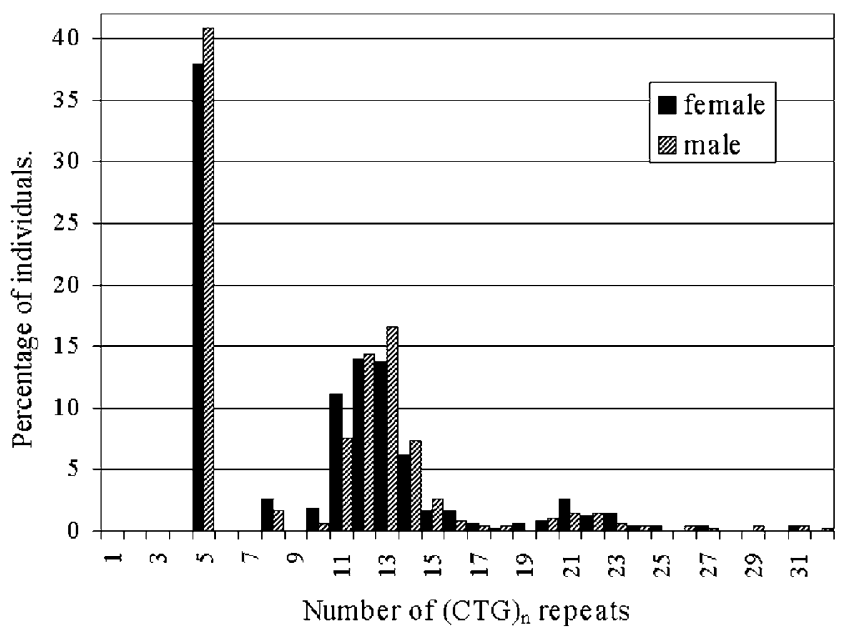

Figure 1 Distribution of DMPK (CTG $)_{n}$ repeat sizes observed in the 234 study couples $(N=936$ alleles $)$. as study couples. Analysis of the DMPK alleles of these individuals showed a tri-modal distribution of $(\mathrm{CTG})_{n}$ repeat size similar to that previously observed in other populations of predominantly European ancestry (Figure 1). ${ }^{21,26,27}$ The sample was found to be in HardyWeinberg equilibrium $(P=0.4)$. This suggests that although our study group was a selected group that had difficulty to conceive, it was not different from the general population with respect to the distribution of the DMPK alleles. Therefore, our study group could be considered as representing the general population with respect to transmission of DMPK alleles. Of the 234 couples, 62 (26\%) had at least one partner with a Group I/Group II genotype. (Supplementary Information, see Table S1). The largest repeat size observed was (CTG) 32 . Of the 62 couples, 54 donated embryos for research after their IVF cycle was completed (42 couples donated in one cycle, nine couples in two consecutive cycles, and three in three cycles).

The age and IVF parameters of the study couples were analysed. The characteristics of those couples in which there was at least one partner with Group I/Group II genotype were compared to those carrying two Group I repeats. No significant differences were found between the two groups with respect to the age of the male or female partner, fertilisation rate, in vitro blastocyst formation rate, implantation rate, or clinical pregnancy rate (Table 1).

In total, 341 embryos were donated and genotyping results were obtained for 335 embryos. The number of genotyped embryos per couple ranged from one to 16 with a mean and a median of six. Each embryo provided information for two transmissions, one maternal and one paternal, and therefore 670 transmissions were recorded (Table 2).

\section{Transmission ratios of $\mathrm{DMPK}(\mathrm{CTG})_{n}$ repeats}

Among the 335 embryos genotyped, 59\% (95\% confidence interval of 54-64) inherited the Group II repeat from parents with Group I/Group II genotype (Table 3). There-

Table 1 Cycle parameters for the study couples carrying a Group II repeat compared to those who only carried Group I repeats

\begin{tabular}{|c|c|c|c|c|c|c|c|}
\hline Genotypes of couples ${ }^{\mathrm{a}}$ & $\begin{array}{l}\text { No. of } \\
\text { couples }\end{array}$ & $\begin{array}{c}\text { Average female } \\
\text { age (range) }\end{array}$ & $\begin{array}{c}\text { Average male } \\
\text { age (range) }\end{array}$ & $\begin{array}{l}\text { Fertilisation } \\
\text { rate (\%) }\end{array}$ & $\begin{array}{c}\text { Blastocyst } \\
\text { formation } \\
\text { rate (\%) }\end{array}$ & $\begin{array}{l}\text { Implantation } \\
\text { rate }^{\mathrm{b}}(\%)\end{array}$ & $\begin{array}{c}\text { Clinical } \\
\text { pregnancy } \\
\text { rate }^{c}(\%)\end{array}$ \\
\hline $\begin{array}{l}\text { At least one parent } \\
\text { with a Group I and a } \\
\text { Group II repeat }\end{array}$ & 62 & $34.9(22-43)$ & $37.4(23-51)$ & 60.5 & 34 & 26 & 46 \\
\hline $\begin{array}{l}\text { Both parents with } \\
\text { Group I repeats }\end{array}$ & 171 & $34.9(20-43)$ & $37.6(22-51)$ & 59.7 & 35 & 20 & 43 \\
\hline
\end{tabular}

${ }^{a} N=233$ couples; one couple in which the paternal genotype was Group I homozygous and the maternal genotype was Group II/Group II was not included in this table. Group I repeat $=D M P K(C T G)_{5-18}$; Group II repeat $=D M P K(C T G)_{19-37}$.

${ }^{b}$ Implantation rate is defined as the total number of sacs seen at 6-week ultrasound divided by the total number of embryos transferred to the uterus of the female patient at embryo transfer.

${ }^{c}$ Clinical pregnancy rate is defined as ultrasound evidence of pregnancy seen at 6 weeks of pregnancy. 
fore, we detected a statistically significant deviation from Mendelian 1:1 segregation in the embryos $(P=0.0004$, exact binomial test). TRD in favour of the Group II repeat was observed following both maternal and paternal transmissions $(60 \%, P=0.0055$ and $59 \%, P=0.03$, respectively), although with correction for multiple testing, the significance level $(P<0.0056)$ was reached only in maternal transmissions. When sex of the embryo was considered, a greater magnitude of TRD was observed among female rather than male embryos $(65 \%, P=0.0001$ and $55 \%$, $P=0.2$, respectively).

To determine if the preferential transmission of the longer DMPK repeat in individuals with a Group I/Group II genotype was due to a relative repeat size effect (as

Table 2 Number of transmissions observed in our study by parental genotype

\begin{tabular}{|c|c|c|}
\hline $\begin{array}{l}\text { DMPK genotype of the } \\
\text { parent }^{\mathrm{a}}\end{array}$ & $\begin{array}{l}\text { No. of parents } \\
\text { (mothers/ } \\
\text { fathers) }\end{array}$ & $\begin{array}{c}\text { No. of } \\
\text { transmissions } \\
\text { observed }\end{array}$ \\
\hline $\begin{array}{l}\text { Group I/Group II } \\
\text { Group I/Group I } \\
\text { heterozygous }\end{array}$ & $\begin{array}{l}61(34 / 27) \\
33(16 / 17)\end{array}$ & $\begin{array}{l}371^{\mathrm{b}} \\
225^{\mathrm{c}}\end{array}$ \\
\hline $\begin{array}{l}\text { Group I/Group I } \\
\text { homozygous }\end{array}$ & $13(4 / 9)$ & $68^{d}$ \\
\hline $\begin{array}{l}\text { Group II/Group II } \\
\text { heterozygous }\end{array}$ & $1(0 / 1)$ & $6^{e}$ \\
\hline Total & $108(54 / 54)$ & 670 \\
\hline
\end{tabular}

${ }^{\text {a Group I repeat }=D M P K \quad(\mathrm{CTG})_{5-18} ; \text { Group II repeat }=D M P K}$ (CTG) $19-37$.

Includes 36 embryos (72 transmissions) where both parents had a Group I/Group II genotype. These 371 transmissions were used to examine TRD in Group I versus Group II repeats (Table 3).

${ }^{c}$ These 225 transmissions were used to examine if TRD could be due a relative repeat size effect irrespective of the allele type, that is, transmission of 'Short' versus 'Long' allele.

${ }^{d} 68$ transmissions from Group I/Group I homozygous parents were uninformative because they could only transmit one particular (CTG) repeat.

e Six transmissions in which the father had two different sized Group II repeats were excluded from the analysis due to the small sample size. proposed by Chakraborty et $a l^{5}$ ) or whether it was due to preferential transmission of the Group II repeat, the 225 transmissions from informative Group I/Group I parents, who were heterozygous for $(\mathrm{CTG})_{5-18}$ repeats, were analysed. The transmission of the Group I repeats to the embryos were recorded with the smaller repeat present designated as 'Short' and the larger as 'Long' irrespective of the actual size of the repeat. That is, the same allele could be designated as 'Short' or 'Long' dependent upon the length of the other parental repeat. For example, in an individual with a $(\mathrm{CTG})_{5} /(\mathrm{CTG})_{11}$ genotype, the $(\mathrm{CTG})_{11}$ was considered as 'Long'. However, in an individual with a $(\mathrm{CTG})_{11} /(\mathrm{CTG})_{14}$ genotype, the $(\mathrm{CTG})_{11}$ was considered as 'Short'. The 'Long' allele was transmitted to the embryo in $46 \%(104 / 225, P=0.3)$ of transmissions (Supplementary Information, see Table S2). Thus, in our study, we observed TRD in favour of the larger allele only from individuals with Group I/Group II genotype.

\section{Discussion}

We report here, for the first time, preferential transmission (59\%) of larger DMPK alleles (Group II repeats, (CTG) $19-37$ ) compared to smaller alleles (Group I repeats, $(\mathrm{CTG})_{5-18}$ ) to preimplantation embryos and showed this was specifically due to the presence of the Group II repeat. These results support the observation, of TRD in favour of Group II repeats, in the live-born offspring of couples with at least one parent with Group I/Group II genotype (56\% Group II, $N=150 / 266$ transmissions; $P=0.04$, exact binomial test $)^{3}$ (Supplementary Information, see Table S3).

This finding advances our knowledge concerning the timing of TRD in Group II repeats. Leeflang et al. ${ }^{20}$ had previously excluded segregation distortion for Group I versus Group II repeats in the male germline as a possible mechanism of TRD and hypothesized that TRD resulted from events following sperm ejaculation. Our results further narrow the time period when the TRD is generated, and suggest that TRD results from events preceding preimplantation development (Figure 2). In principle,

Table 3 Transmission of DMPK (CTG) $)_{\mathrm{n}}$ repeats to embryos ${ }^{\mathrm{a}}$

\begin{tabular}{|c|c|c|c|c|c|c|c|c|c|c|c|c|}
\hline \multirow[b]{2}{*}{$\begin{array}{l}\text { Parental origin } \\
\text { of the alleles }\end{array}$} & \multicolumn{4}{|c|}{ Female embryos } & \multicolumn{4}{|c|}{ Male embryos } & \multicolumn{4}{|c|}{ Embryos of both sexes } \\
\hline & Group I & Group II & $T_{G I l}(\%)$ & $95 \% \mathrm{Cl}$ & Group I & Group II & $T_{G I I}(\%)$ & $95 \% \mathrm{Cl}$ & Group I & Group II & $T_{G I I}(\%)$ & $95 \% \mathrm{Cl}$ \\
\hline $\begin{array}{l}\text { Maternal } \\
\text { Paternal } \\
\text { Total }\end{array}$ & $\begin{array}{l}33 \\
25 \\
58\end{array}$ & $\begin{array}{r}64 \\
44 \\
108\end{array}$ & $\begin{array}{l}66^{b} \\
64^{c} \\
65^{d}\end{array}$ & $\begin{array}{l}56-75 \\
51-75 \\
57-72\end{array}$ & $\begin{array}{l}51 \\
42 \\
93\end{array}$ & $\begin{array}{r}61 \\
51 \\
112\end{array}$ & $\begin{array}{l}54 \\
55 \\
55\end{array}$ & $\begin{array}{l}45-64 \\
41-65 \\
48-62\end{array}$ & $\begin{array}{r}84 \\
67 \\
151\end{array}$ & $\begin{array}{r}125 \\
95 \\
220\end{array}$ & $\begin{array}{l}60^{b} \\
59^{c} \\
59^{d}\end{array}$ & $\begin{array}{l}53-67 \\
51-66 \\
54-64\end{array}$ \\
\hline
\end{tabular}

${ }^{\mathrm{a}}$ Group I repeat $=\mathrm{DMPK}(\mathrm{CTG})_{5-18}$; Group II repeat $=$ DMPK $(\mathrm{CTG})_{19-37} ; \mathrm{T}_{\mathrm{GII}}=$ percent of embryos inheriting the $\mathrm{Group} \mathrm{II} \mathrm{repeat;} 95 \% \mathrm{Cl}=95 \%$ confidence interval.

${ }^{\mathrm{b}}$ Significant transmission ratio distortion from $1: 1$ at $P<0.01$.

'Significant transmission ratio distortion from 1:1 at $P<0.05$.

${ }^{\mathrm{d}}$ Significant transmission ratio distortion from 1:1 at $P<0.0005$ 


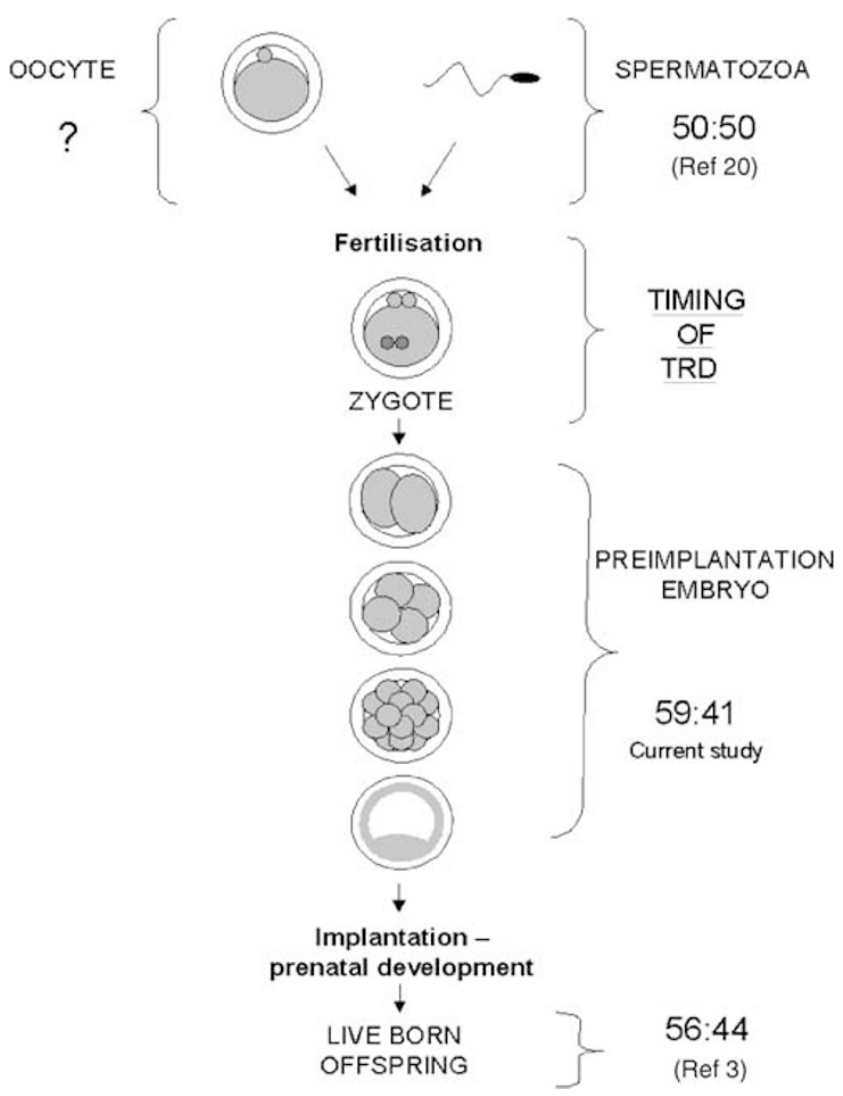

Figure 2 Transmission ratios for Group II repeats ((CTG) 19-37) versus Group I repeats $\left((\mathrm{CTG})_{5-18}\right)$ at the DMPK locus at different stages of human development including the findings of the current study. TRD in favour of Group II repeats at the DMPK locus is likely to occur at or around the time of fertilisation as indicated in the diagram.

these events could be preferential fertilisation of oocytes by Group II repeat-bearing sperm, preferential retention of Group II repeats in the oocytes, preferential survival of Group II repeat-bearing gametes, or meiotic drive in the female germline at the time of the second meiotic division favouring generation of heterozygous embryos with a Group I/Group II genotype. Meiotic drive at the second meiotic division has been reported for maternal transmissions at the mouse $\mathrm{Om}$ locus. ${ }^{28}$ We think that preimplantation embryo loss and postimplantation lethality are unlikely causes of TRD in our study group, as we included all donated embryos, even those arrested in their development, and demonstrated a magnitude of TRD (59\%) in preimplantation embryos similar to the one reported for live-born offspring $(56 \%))^{3}$

Our results showed TRD from both maternal and paternal transmissions (60 and 59\%, respectively), which, for this work, reached the threshold for level of significance only in maternal transmissions. Carey et al. ${ }^{3}$ also found TRD in Group II repeats to live-born offspring, in families with no known history of myotonic dystrophy, although it was stronger from paternal (60\%) than from maternal transmission (55\%). On reanalysis of this data by another group, no evidence was found to support a male specific TRD but, similar to our results, a statistically significant TRD in favour of Group II repeats acting in both sexes was demonstrated. ${ }^{29}$ In another study examining TRD in liveborn offspring from CEPH pedigrees, which represent families selected for high fertility and longevity, no TRD was found in the small subset of transmissions with Group I/Group II genotype (49\% Group II, $N=46 / 94$ transmissions), which may be due to the sample size. ${ }^{5}$ (Supplementary Information, see Table S3)

Three studies reported TRD in myotonic dystrophy pedigrees (251 Italian and Spanish pedigrees, 69 Brazilian families, and 59 pedigrees in Northern Ireland), which for purposes of comparison we consider as DM1., ${ }^{4,7}$ (Supplementary Information, see Table S4) These studies reported the number of affected and unaffected offspring born to parents with DM1. In the combined data, TRD in favour of the DMPK allele was similar from affected fathers as compared to affected mothers (56 and 54\%, respectively). Our results also demonstrate a similar degree of TRD for Group II repeats from both paternal and maternal transmissions, although the mechanism of TRD of Group II repeats may not be the same as for TRD of highly expanded repeats causing DM1.

When the male and female embryos in our study were considered separately, a statistically significant TRD in favour of Group II repeats was seen in female embryos following both maternal and paternal transmissions. These findings are in contrast to the greater degree of TRD in sons compared to daughters in the DM pedigrees ${ }^{4,6,7}$ (Supplementary Information, see Table S4), but as previously mentioned the mechanism of TRD of Group II repeats may not be the same as in highly expanded repeats. Unfortunately, none of the studies looking at TRD of larger normalsize DMPK alleles reported their data by gender of offspring so we were unable to compare our results with the ratios occurring in live-born offspring. The absence of statistically significant TRD in our male embryos could result from limited numbers of embryos tested or alternatively, could be due to a difference in the mode of transmission of Group II repeats to males compared to females. One possible explanation for differences in the magnitude of TRD dependent on the sex of the offspring is the presence of modifiers on the $\mathrm{X}$ and/or Y-chromosomes affecting embryo survival or causing preferential transmission of a particular parental allele. ${ }^{30-32}$ Another possibility is the genetic heterogeneity of individuals with respect to transacting factors involved in the genesis of TRD. ${ }^{8,9}$

The TRD in our embryos was due to the Group II repeat specifically rather than an overall relative allele size effect, as demonstrated by no significant TRD in transmissions from informative Group I/Group I parents. The low frequencies of individual Group II alleles and insufficient 
number of observations for each particular Group II allele do not allow us to determine if a particular subgroup of Group II alleles drives the TRD. In contrast to our results, two other studies found preferential transmission of the 'Long' allele (compared to the 'Short' allele, irrespective of the absolute size) in maternal transmission. ${ }^{5,19}$ (Supplementary Information, see Table S3) However, the repeat size in these studies ranged from $(\mathrm{CTG})_{5-30}$, which was different from the $(\mathrm{CTG})_{5-18}$, in our analysis.

It could be suggested that the TRD in favour of Group II repeats, as demonstrated in embryos donated from IVF patients, was an effect of testing infertile couples rather than the general population. However, the distribution of the DMPK alleles within our study, which was not selected for ethnicity, but was largely French Canadian, showed a similar tri-modal pattern and prevalence of $(\mathrm{CTG})_{5}$ repeats as previously observed in other populations of predominantly European ancestry (Figure 1). ${ }^{21,26,27}$ If infertility were associated with a change in transmission patterns, one would expect this to be reflected in the distribution of allele frequencies.

Furthermore, we did not find any differences in the embryos from couples where at least one partner had Group I/Group II genotype and couples where both partners had Group I/Group I genotype with respect to age or measurable IVF outcomes (Table 1). In particular, the quality of donated embryos as assessed by the percentage that developed to the blastocyst stage on day six of in vitro culture was similar in both genotypic groups demonstrating that the presence of a Group II repeat did not influence preimplantation embryo development (Table 1). From this finding we assume that the DMPK allele distribution in the donated embryos was similar to the distribution of embryos transferred to the female patient. Therefore, it is unlikely that the TRD observed in our IVF embryos was caused by the infertility of the parents or that the presence of a Group II repeat was linked to infertility. It is also unlikely that the IVF hormonal treatment undertaken by the women influenced the allelic transmission. However, it is not possible to exclude the effects of additional genes downstream of $D M P K$, which could influence the transmission process of DMPK alleles. A lack of association of DMPK genotype with fertility parameters is consistent with normal fertility for women carrying DMPK (CTG) $50-150$ repeats. ${ }^{33,34}$ Although fertility can be compromised in males with mild or severe DM1, ${ }^{16,35}$ the fathers in our study carried repeat sizes within the normal range, and therefore, no reduction in fertility due to $(\mathrm{CTG})_{n}$ repeat size would be expected in our study group.

In conclusion, TRD in favour of Group II repeats from both mothers and fathers with two normal-size DMPK $(\mathrm{CTG})_{n}$ repeats, one Group I and one Group II, was observed in human preimplantation embryos. The TRD was stronger in female compared to male embryos. This TRD was due to the presence of the Group II repeats specifically and not the relative size of the (CTG) ${ }_{n}$ repeats. It is likely to have occurred at or around the time of fertilisation. Further studies of the transmission of the DMPK $(\mathrm{CTG})_{n}$ repeats are needed to identify the factors responsible for the TRD observed at the DMPK locus and the compensatory factors to maintain the normal-size alleles in the population.

\section{Acknowledgements}

We are grateful to the couples that donated embryos for the study, Dr Dewen Kong for his technical assistance, the clinical embryologists at the McGill Reproductive Centre, and Mr Fabrice Rouah of the McGill University Statistical Consulting Service. NLD is partially supported in the PhD program by an academic award from the Department of Experimental Medicine. AKN is a Canadian Institutes of Health Research (CIHR) New Investigator. This research was supported by the McGill Reproductive Centre, Obstetrics and Gynecology, McGill University (to $A A$ ) and operating grant from the Canadian Genetic Diseases Network, Network of Centres of Excellence program (to KM).

\section{References}

1 Lyttle TW: Cheaters sometimes prosper: distortion of Mendelian segregation by meiotic drive. Trends Genet 1993; 9: 205-210.

2 Eaves IA, Bennett ST, Forster P et al: Transmission ratio distortion at the INS-IGF2 VNTR. Nat Genet 1999; 22: 324-325.

3 Carey N, Johnson K, Nokelainen P et al: Meiotic drive at the myotonic dystrophy locus? Nat Genet 1994; 6: 117-118.

4 Gennarelli M, Dallapiccola B, Baiget M, Martorell L, Novelli G: Meiotic drive at the myotonic dystrophy locus. J Med Genet 1994; 31: 980-982.

5 Chakraborty R, Stivers D, Deka R, Yu L, Shriver M, Ferrell R: Segregation distortion of the CTG repeats at the myotonic dystrophy locus. Am J Hum Genet 1996; 59: 109-118.

6 Zatz M, Cerqueira A, Vainzof M, Passos-Bueno MR: Segregation distortion of the CTG repeats at the myotonic dystrophy (DM) locus: new data from Brazilian DM families. J Med Genet 1997; 34: 790-791.

7 Magee AC, Hughes AE: Segregation distortion in myotonic dystrophy. J Med Genet 1998; 35: 1045-1046.

8 Ikeuchi T, Igarashi S, Takiyama Y et al: Non-Mendelian transmission in dentatorubral-pallidoluysian atrophy and MachadoJoseph disease: the mutant allele is preferentially transmitted in male meiosis. Am J Hum Genet 1996; 58: 730-733.

9 Reiss O, Epplen JT, Amoiridis G, Przuntek H, Schols L: Transmission distortion of the mutant alleles in spinocerebellar ataxia. Hum Genet 1997; 99: 282-284.

10 Iughetti P, Otto PA, Zatz M, Passos Bueno MR, Marie SK: Different behavior in the paternally $v s$ maternally inherited mutated allele in Brazilian Machado-Joseph (MJD1) families. Am J Med Genet 1998; 77: 246-248.

11 Drasinover V, Ehrlich S, Magal N et al: Increased transmission of intermediate alleles of the FMR1 gene compared with normal alleles among female heterozygotes. Am J Med Genet 2000; 93: $155-157$.

12 Monckton DG, Cayuela ML, Gould FK, Brock GJ, Silva R, Ashizawa T: Very large $(C A G)(n)$ DNA repeat expansions in the sperm of two spinocerebellar ataxia type 7 males. Hum Mol Genet 1999; 8: 2473-2478.

13 Harper PS, Harley HG, Reardon W, Shaw DJ: Anticipation in myotonic dystrophy: new light on an old problem. Am J Hum Genet 1992; 51: 10-16.

14 Brook JD, McCurrach ME, Harley HG et al: Molecular basis of myotonic dystrophy: expansion of trinucleotide (CTG) repeat at 
$3^{\prime}$ end of a transcript encoding a protein kinase family member. Cell 1992; 68: 799-808.

15 Mahadevan M, Tsilfidis C, Sabourin L et al: Myotonic dystrophy: an unstable CTG repeat in the $3^{\prime}$ untranslated region of the gene. Science 1992; 255: 1253-1255.

16 Harper PS: Myotonic dystrophy; in Rimoin DL, Connor JM, Pyeritz RE (eds): Emery and Rimoin's principles and practice of medical genetics. New York: Churchill Livingstone, 1997, 3rd edn, pp 2425-2443.

17 Buxton J, Shelbourne P, Davies J et al: Detection of an unstable fragment of DNA specific to individuals with myotonic dystrophy. Nature 1992; 355: 547-548.

18 Harley HG, Rundle SA, MacMillan JC et al: Size of the unstable CTG repeat sequence in relation to phenotype and parental transmission in myotonic dystrophy. Am J Hum Genet 1993; 52: $1164-1174$.

19 Shaw AM, Barnetson RA, Phillips MF, Harper PS, Harley HG: Evidence for meiotic drive at the myotonic dystrophy locus. J Med Genet 1995; 32: 145A (Abstract).

20 Leeflang EP, McPeek MS, Arnheim N: Analysis of meiotic segregation, using single-sperm typing: meiotic drive at the myotonic dystrophy locus. Am J Hum Genet 1996; 59: 896-904.

21 Imbert G, Kretz C, Johnson K, Mandel JL: Origin of the expansion mutation in myotonic dystrophy. Nat Genet 1993; 4: 72-76.

22 Dean NL, Tan SL, Ao A: The development of preimplantation genetic diagnosis for myotonic dystrophy using multiplex fluorescent polymerase chain reaction and its clinical application. Mol Hum Reprod 2001; 7: 895-901.

23 Ray PF, Vekemans M, Munnich A: Single cell multiplex PCR amplification of five dystrophin gene exons combined with gender determination. Mol Hum Reprod 2001; 7: 489-494.

24 Findlay I, Ray P, Quirke P, Rutherford A, Lilford R: Allelic drop-out and preferential amplification in single cells and human blastomeres: implications for preimplantation diagnosis of sex and cystic fibrosis. Hum Reprod 1995; 10: 1609-1618.
25 Raymond M, Rousset F: GENEPOP (version 1.2): population genetics software for eact tests and ecumenicism. J Hered 1995; 86: $248-249$.

26 Zerylnick C, Torroni A, Sherman SL, Warren ST: Normal variation at the myotonic dystrophy locus in global human populations. Am J Hum Genet 1995; 56: 123-130.

27 Deka R, Majumder PP, Shriver MD et al: Distribution and evolution of CTG repeats at the myotonin protein kinase gene in human populations. Genome Res 1996; 6: 142-154.

$28 \mathrm{Wu}$ G, Hao L, Han Z et al: Maternal transmission ratio distortion at the mouse Om locus results from meiotic drive at the second meiotic division. Genetics 2005; 170: 327-334.

29 Hurst GD, Hurst LD, Barrett JA: Meiotic drive and myotonic dystrophy. Nat Genet 1995; 10: 132-133.

30 Naumova AK, Leppert M, Barker DF, Morgan K, Sapienza C: Parental origin-dependent, male offspring-specific transmissionratio distortion at loci on the human X chromosome. Am J Hum Genet 1998; 62: 1493-1499.

31 de la Casa-Esperon E, Pardo-Manuel de Villena F, Verner AE et al: Sex-of-offspring-specific transmission ratio distortion on mouse chromosome X. Genetics 2000; 154: 343-350.

32 Zollner S, Wen X, Hanchard NA, Herbert MA, Ober C, Pritchard $\mathrm{JK}$ : Evidence for extensive transmission distortion in the human genome. Am J Hum Genet 2004; 74: 62-72.

33 Dao TN, Mathieu J, Bouchard JP, De Braekeleer M: Fertility in myotonic dystrophy in Saguenay-Lac-St-Jean: a historical perspective. Clin Genet 1992; 42: 234-239.

34 Lavedan C, Hoffman-Radvanyi $\mathrm{H}$, Shelbourne $\mathrm{P}$ et al: Myotonic dystrophy: size and sex dependent dynamics of CTG meiotic instability and somatic mosaicism. Am J Hum Genet 1993; 52: $875-883$.

35 Hortas ML, Castilla JA, Gil MT et al: Decreased sperm function of patients with myotonic muscular dystrophy. Hum Reprod 2000; 15: $445-448$.

Supplementary Information accompanies the paper on European Journal of Human Genetics website (http://www.nature.com/ejhg). 